\title{
EDITORIAL
}

\section{The editors' farewell and a confident look back to the} future

\author{
Anh Tuan Dinh-Xuan* and Vito Brusasco ${ }^{\#}$
}

$\mathbf{T}$ he first issue of the European Respiratory Journal (ERJ) was published in January 1988 [1], 2 years before the birth of the European Respiratory Society (ERS) [2]. The $E R J$ was not an ex nihilo creation, neither was it a transformation from one single predecessor journal. Rather, the ERJ came to life from a remarkable joint effort of two distinct and yet complementary journals, namely the Bulletin Européen de Physiopathologie Respiratoire and the European Journal of Respiratory Diseases, merging their scientific spirit [3] and human resources [4] to give birth to the present journal, which is now on the eve of celebrating its 25th birthday.

Prof. Erik Berglund and the late Prof. Jean-Claude Yernault [5] were the first joint chief editors of the journal. Together they set the ERJ in motion during its first 2 years (1988-1990). They were followed in their chief editorship by the late Prof. Paul Vermeire (1990-1995) [6], and subsequently by Profs Ulrich Costabel (1994-1999) [7], Marc Decramer (2000-2002) [8], and Peter Sterk and Klaus Rabe (2003-2008) [9]; all still are actively contributing to the journal as authors, reviewers and/or advisors.

When we started our editorship in January 2009, the ERJ was just entering its 21st year, a symbolic number that, not so long ago, also represented the starting point of adulthood and maturity for mankind [10]. During the past 48 months, and with the help of 32 associate editors, we have reviewed almost 9,000 manuscripts, of which only around 1,200 have been accepted. With slightly less than $15 \%$ rate of acceptance, the $E R J$ has now undoubtedly become one of the most competitive journals in the respiratory field [11]. Yet the journal has never been so popular when one looks at the number of submitted manuscripts. In the early 1990s, the ERJ only received around 400 manuscripts per year [12]; this number has progressively risen to reach a five-fold increase two decades later (fig. 1) [13]. The increase in submissions has been not only numerical, but also geographical, as the ERJ has received, in 2010, manuscripts from 62 different countries coming from the five continents (fig. 2). As a result, the ERJ is now becoming a truly intercontinental journal with the number of papers from outside Europe now accounting for $40 \%$ of the total number of submitted manuscripts [13].

*Dept of Cardiopulmonary Medicine, Cochin Hospital, University Paris Descartes, Paris, France. ${ }^{*}$ Dept of Internal Medicine, Medical School, University of Genoa, Genoa, Italy.

CORRESPONDENCE: A.T. Dinh-Xuan, Service de Physiologie-Explorations Fonctionnelles, Hôpital Cochin, 27 rue du faubourg Saint-Jacques, 75104 Paris, France. E-mail: anh-tuan.dinhxuan@cch.aphp.fr

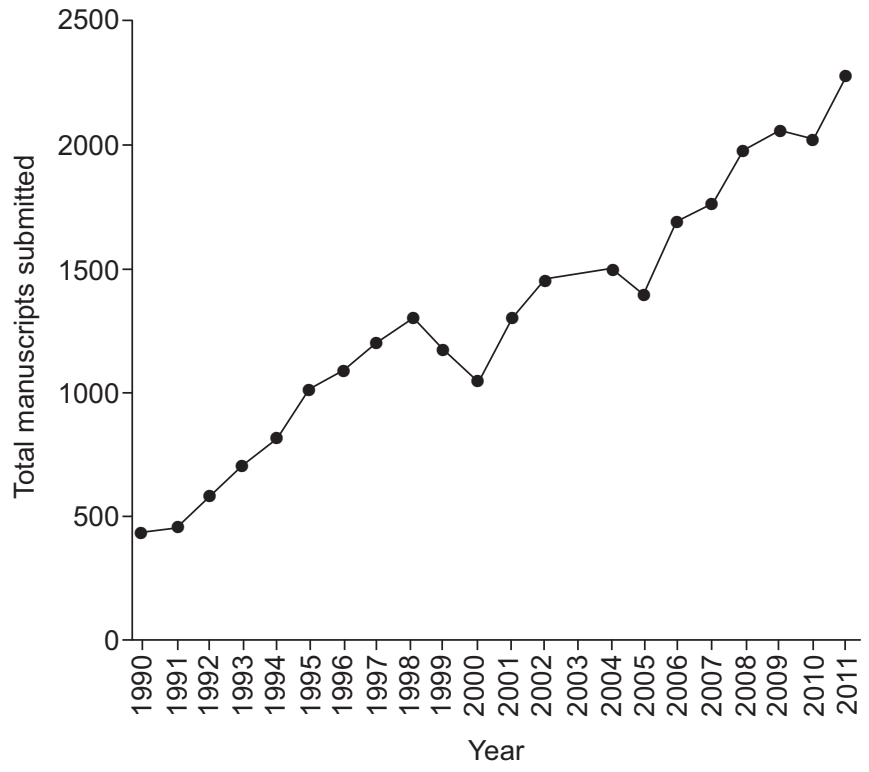

FIGURE 1. Number of manuscripts submitted to the European Respiratory Journal during the past two decades $[12,13]$.

With such a high number of submissions, and only $15 \%$ rate of acceptance, a vast majority of our authors unavoidably have received negative answers from the ERJ editorial team. In all cases, these negative answers have been made with all the necessary esteem and consideration for the numerous authors who have trusted the journal with submissions of their work. Whenever possible, we tried to reduce the verdict time as much as we could, and irrespective of the nature of the final decision, we always tried our best to provide the authors with clear, detailed and helpful comments reflecting the scientific evaluation of their work, in an attempt to improve the scientific impact of manuscripts that will eventually be published elsewhere [14].

As the primary aim of an editorial evaluation is to contribute to the scientific quality of a given manuscript, irrespective of its publication fate, i.e. rejection or acceptance, those that eventually get published in the journal are read by an increasing number of readers, and eventually get more and more cited. As a result, the impact factor of the $E R J$ has steadily risen during the past 20 years, from just above 1 in 1990 to almost reach the symbolic threshold of 6 for the past 2 years (fig. 3). One might argue that a majority of scientific and medical journals also improved their impact factors during the past decade [15], and 


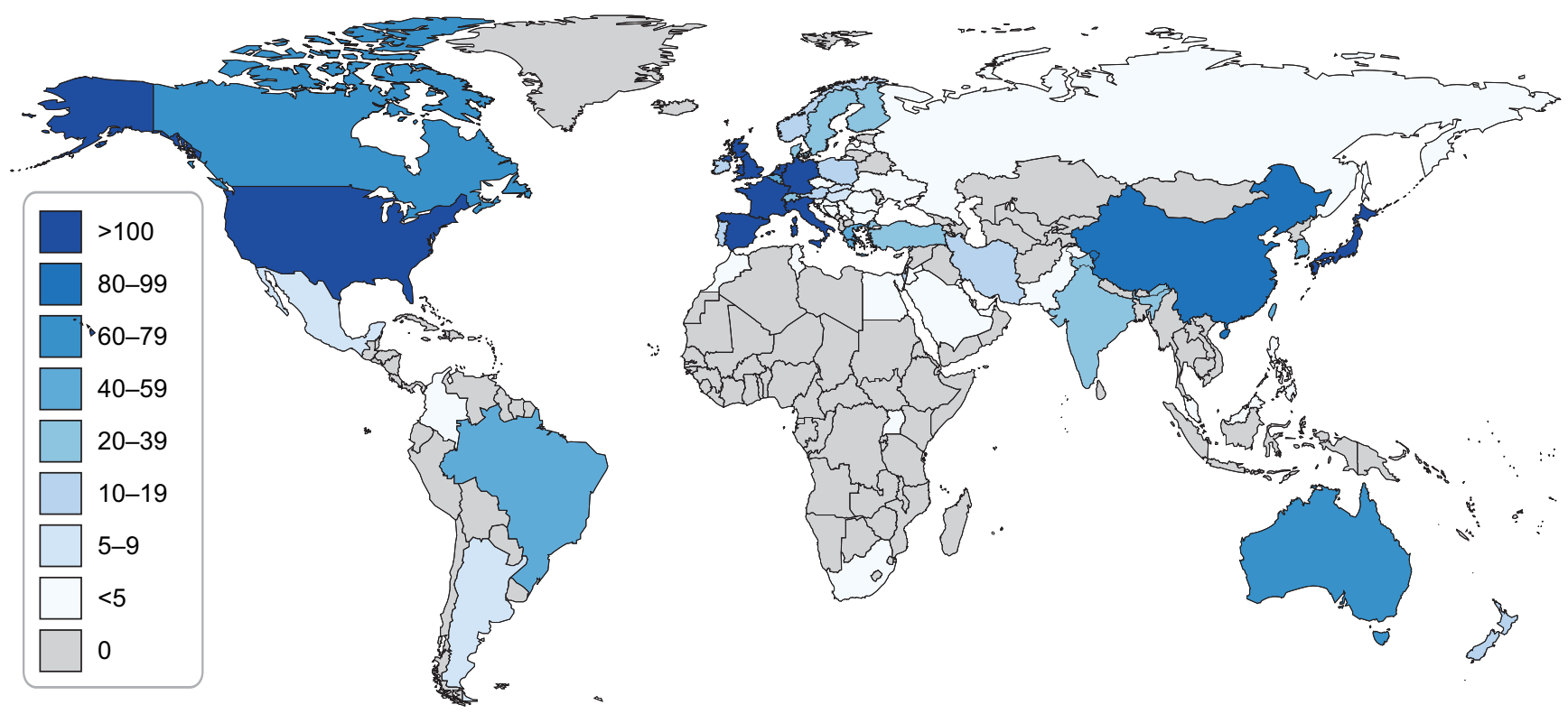

FIGURE 2. Geographical origins of manuscripts submitted to the European Respiratory Journal (ERJ) in 2010. The ERJ received papers from 62 countries from five continents.

that the absolute numerical value of the impact factor does not fully reflect the quality and importance of a scientific journal [16]. Looking at the position of the ERJ and comparing it with other journals in the respiratory field, we are reassured by the fact that the ERJ not only has increased its impact factor but also has improved its status, becoming one of the prominent respiratory journals while making its way through from the top $30 \%$ (in the early years of this new century) to the current top $5 \%$ of journals from the respiratory field (fig. 3).

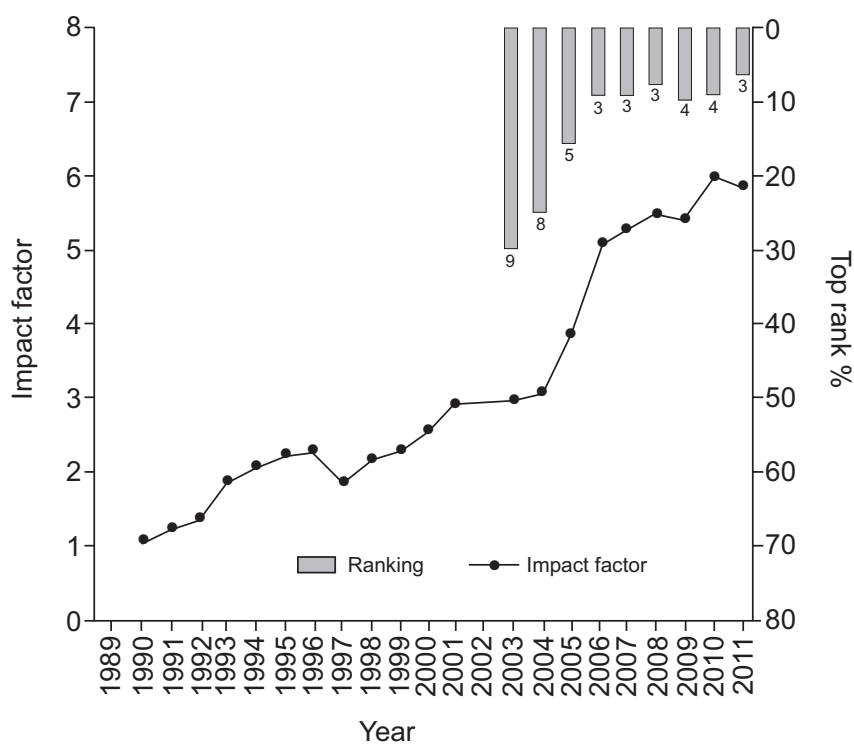

FIGURE 3. Trends of impact factors of the European Respiratory Journal (ERJ) from 1990 to 2010 [12]. The bars depict the ranking of the journal as reflected by the ratio of the rank of the ERJ divided by the total number of journals in the respiratory field. For example, in 2011 the ERJ was ranked third (as indicated on the bar) of a total of 48 respiratory journals, thus being in the top $6 \%$.
After 4 years of almost daily editorial work, the current editors are now preparing to hand the ERJ over to the new editorial team. As with the previous transfer of editorial duties, the next one will be smooth and progressive, with some of the current editors staying on board to continue their work with new and enthusiastic editors who will make their entries in the ERJ for the first time, to work with the new editor-in-chief, Prof. Marc Humbert. Marc is no stranger neither to members of the ERS, being a brilliant recipient of the 2006 Cournand Lecture, nor to the readers of both the European Respiratory Review, which he has masterfully headed as chief editor from 2009 to date [17], and the ERJ, where he has put a tremendous effort as associate editor to attract and edit seminal papers on asthma and pulmonary hypertension (two domains of Marc's numerous expertise). Before handling the ERJ editorial

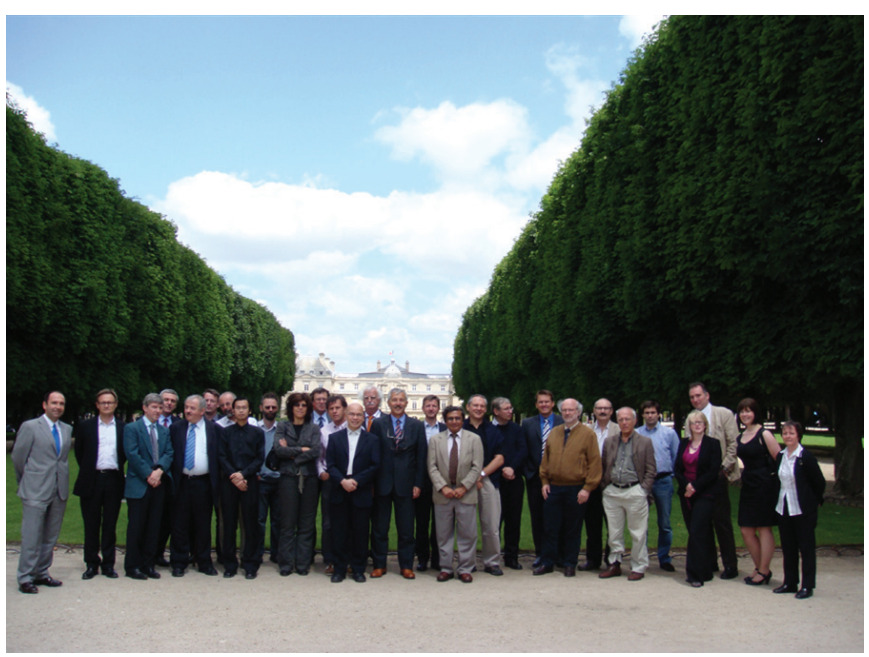

FIGURE 4. Picture of some of the members of the European Respiratory Journal editorial board and publications office taken at the Garden of Luxemburg during the first editorial board meeting (June 2009, Paris, France). 
duties to the new editor-in-chief, it is our privilege and pleasure to express all our gratitude to members of the editorial board and the ERS publications office in Sheffield (fig. 4).

It is remarkable that, even with the change of the chief editorship, about one third to half of members of the current editorial board will stay and continue the journey with the new editor-in-chief, making the renewal a smooth and progressive transitional process. We are sure that all current, past and future $E R J$ editors will keep in mind the lessons learned from the past in order to better serve in the future, with the legitimate confidence of persons who remember where they come from before heading for new tasks and ambitions, but with always an invariable aim to serve the journal and its readers.

\section{STATEMENT OF INTEREST}

None declared.

\section{REFERENCES}

1 Berglund E, Yernault JC. The new European Respiratory Journal. Eur Respir J 1988; 1: 1.

2 Siafakas NM. The European Respiratory Society, 1990-2010: a 20year anniversary story of success. Eur Respir J 2010; 35: 1-2.

3 Puchelle E, Quanjer PH, Lockhart A, et al. Prof. Paul Sadoul, 1918-2011. Eur Respir J 2011; 38: 1245-1247.

4 Howard P. In memoriam Wendy Thompson, 1944-2008. Eur Respir J 2009; 33: 457-458.
5 Vermeire P, De Vuyst P. In memoriam Jean-Claude Yernault, 1943-2004. Eur Respir J 2005; 25: 1-2.

6 Decramer M, Berglund E, Costabel U, et al. In memoriam Professor Paul Vermeire, 1936-2007: a tribute from the ERJ Chief Editors. Eur Respir J 2007; 30: 819-820.

7 Costabel U. On the continued growth of the ERJ. Eur Respir J 1996; 9: $1-2$.

8 Decramer M. The ERJ into the new millennium. Eur Respir J 2000; 15: 1-2.

9 Sterk PJ, Rabe KF. You've got mail: erj@lumc.nl. Eur Respir J 2003, 21: 1-2.

10 Dinh-Xuan AT, Brusasco V. The ERJ in its 21st year of age: a smooth transition for an everlasting evolution. Eur Respir J 2009; 33: 1-2.

11 Dinh-Xuan AT, Brusasco V. The making of the ERJ: behind the scenes and Editors' cut. Eur Respir J 2010; 36: 4-5.

12 Decramer M. Goodbye. Introducing the new Chief Editors: Peter Sterk and Klaus Rabe. Eur Respir J 2002; 20: 1357-1358.

13 Dinh-Xuan AT, Brusasco V, Wedzicha JA, et al. ERS publications: the flagship and the fleet. Eur Respir J 2012; 40: 535-537.

14 Calcagno V, Demoinet E, Gollner $\mathrm{K}$, et al. Flows of research manuscripts among scientific journals reveal hidden submission patterns. Science 2012 [Epub ahead of print DOI: 10.1126/ science.1227833].

15 Irwin RS, Augustyn N. The journal and 2011: a time for stocktaking. Chest 2011; 139: 2-5.

16 Rizkallah J, Sin DD. Integrative approach to quality assessment of medical journals using impact factor, eigen factor, and article influence scores. PLoS One 2010; 5: e10204.

17 Humbert M. Introducing the new European Respiratory Review. Eur Respir J 2009; 33: 466-467. 